\title{
Originalien
}

\section{Diagnostische Bedeutung der Proteinbindung von Plasmacortisol, bestimmt durch Dextrangelfiltration* **}

\author{
W. Hoohfreuser, F. Marguth, M. Müllerr-Bardorfi, K. Schwarz, P. C. Scriba und H. Thimle \\ II. Medizinische Klinik der Universität München (Direktor: Prof. Dr. Dr. G. BodmonTmL) \\ und Neurochirurgische Klinik der Universität München (Direktor: Prof. Dr. F. MaraUTH)
}

Cortisol und Corticosteron sind im menschlichen Blut überwiegend proteingebunden. Zirkulierendes Cortisol ist bei Plasmaspiegeln bis zu 20 oder maximal $30 \mu \mathrm{g}-\%$ zum größten Teil an ein spezifisches Globulin mit hoher Bindungsaffinität, jedoch relativ geringer Kapazität gebunden [7, 10-13, 75, 79]. Bei weiterem Anstieg des Plasmacortisolspiegels, z. B. nach Stimulierung der Corticosteroidsekretion durch ACTH oder bei exogener Zafuhr, wird die Bindungskapazität des cortisolbindenden Globulins $\left(\mathrm{CBG}^{1}=\right.$ Transcortin) überschritten und mehr Cortisol frei bzw. an Albumin und Erythrocyten [21] gebunden. Die Bindungsfähigkeit des Albumins ist bei $37^{\circ} \mathrm{C}$ jedoch $7000 \mathrm{mal}$ geringer [87] als die des CBG, und die der Erythrocyten ist noch niedriger. Trotz der ca. $2700 \mathrm{mal}$ höheren Albumin- als CBG-Konzentration im Plasma findet sich daher bei Gesamtcortisolspiegeln oberhalb des physiologischen Bereiches ein höherer Prozentsatz von nicht proteingebundenem Cortisol.

DAUGHADAY [13] hat 1958 nachgewiesen, daß es sich bei dem $\mathrm{CBG}$ um ein $\alpha_{1}$-Globulin handelt. Fin weitgehend gereinigtes CBG $[73,74]$ aus dem Plasma östrogenbehandelter Männer, ein Glykoprotein, konnte pro Molekül 1 Molekül Cortisol binden und wies ein Molekulargewicht von etwa 45000 auf. Bei noch weitergehender Reinigung [53] wurde das Molekulargewicht von CBG mit 51700 angegeben, der Kohlenhydratanteil des Glykoproteins mit etwa $25 \%$.

Die Plasmaproteinbindung von Cortisol hat einen wesentlichen EinfluB auf Transport, Verteilung, biologische Wirkung, Umwandlung und Ausscheidung von Cortisol. Mit ihrer Vehikelfunktion (BENNHOLD) machen die Proteine Cortisol, das nur eine beschränkte Wasserlöslichkeit besitzt, besser löslich. Wahrscheinlich stehen proteingebundenes und freies Cortisol in dynamischem Gleichgewicht (Massenwirkungsgesetz), und die reversible Proteinbindung wirkt nach Art eines Puffers, um die Konzentration des allein biologisch wirksamen [39, 65, 76] freien Cortisols aufrechtzuerhalten $[1,16]$. Das proteingebundene Cortisol stellt somit ein rasch verfügbares, aber zeitweilig inaktiviertes Hormonreservoir dar. Nur der geringe Anteil von nicht proteingebundenem Cortisol, der unter physiologischen Verhältnissen etwa $1 / 10$ des Gesamtgehaltes ausmacht, kann durch die Capillarmembran in die extracelluläre Flüssigkeit passieren $[7,16]$. Wahrscheinlich stehen alle extravasalen Flüssigkeiten (Li-

* Herrn Prof. Dr. Dr. G. BoDechTer zum 70. Geburtstag gewidmet.

** Mit Unterstützung der Deutschen Forsehungsgemeinschaft.

1. $\mathrm{CBG}=$ cortisolbindendes Globulin, Transcortin; 11 OHCS $=11-\mathrm{H} y d r o x y$ corticosteroide; $17-\mathrm{OHCS}=17-\mathrm{Hyd}$ oxycorticosteroide; $\mathrm{PB}^{127} \mathrm{~T}=$ proteingebundenes ${ }^{127} \mathrm{Jod} \mathrm{im}$ Serum; NNR = Nebennierenrinde. quor, Ascites z. B.) im Gleichgewicht mit der geringen Konzentration an freiem Cortisol im Blut [87]. Nur dieses kann durch glomeruläre Filtration ausgeschieden werden $[2,10,67,79]$ und wahrscheinlich ist nur das freie Cortisol dem enzymatischen Abbau in der Leber zugänglich $[1,65,66]$. Vermutlich reagiert auch der negative feed-back-Mechanismus der Regelung derACTH-Sekretion nur auf den freien Cortisolanteil $[33,58]$.

Chemische Bestimmungsmethoden, wie die am häufigsten angewandte Porter-Silber-Reaktion und die fluorimetrischen Methoden, erfassen proteingebundenen und freien Anteil von Cortisol gemeinsam. Zur Bestimmung des proteingebundenen Cortisols im Plasma oder Serum wurden verschiedene Methoden angegeben: Gleichgewichtsdialyse $[7,10,75]$, Ultrafiltration $[8,79]$ sowie Ultrazentrifugation [3], welche sowohl die Bindung an Albumin wie an CBG erfassen. Auch die Erythrocytenaufnahme von radioaktiv markiertem Cortisol kann zu einer indirekten Messung der Proteinbindung benutzt werden [21]. Die Dextrangelfiltration wurde von De Moor [47], von QUincex and GRAY [6I] im Vergleich mit der Gleichgewichtsdialyse, sowie von Dow [19] vor allem zur Bestimmung der Cortisolbindungskapazität des $\mathrm{CBG}$ verwandt. Die Cortisolbindung an Albumin wird bei dieser Methode nicht miterfaßt, da bei der Gelfiltration eine quantitative Dissoziation des Cortisols vom Albumin stattfindet.

Wir haben versucht, die Dextrangelfiltration in Analogie zum $\mathrm{T}_{3}$.Test (Lit. bei [70]) in vitro als diagnostischen Test zur Bestimmung der aktuellen Proteinbindung von Cortisol im Plasma bei endokrinen Krankheiten und bei Störungen der Nebennierenrindenfunktion zu verwenden [54].

\section{Methoden}

1. Die Blutentnahmen erfolgen jeweils gegen $9.00 \mathrm{Uhr}$, um Differenzen im Gesamtcortisolgehalt infolge des cirkadianen Rhythmus auszuschalten $[4,43,55]$. Im Gegensatz zum Gesamtplasmacortisol unterliegt die Bindungskapazität des CBG keinen tageszeitlichen Schwankungen [47]. Das Blut wurde ohne Aspiration in mit Heparin (Liquemin(B) benetzten Zentrifugengläsern aufgefangen und anschließend sofort zentrifugiert. Das Plasma wurde entweder am gleichen Tag benutzt oder bei -15 bis $-20^{\circ} \mathrm{C}$ tiefgefroren. Wir konnten nach mehrmaligem Auftauen und Wiedereinfrieren keine Veränderungen der Cortisolbindung feststellen; auch die Cortisolbindungskapazität wird nicht beeinflußt [63].

2. Inkubationsgemisch: $3 \mathrm{ml}$ Plasma wurden mit $0,1 \mathrm{ml}$ Standardlösung radioaktiv markierten Cortisols bei $37^{\circ} \mathrm{C}$ im Schüttelbad $15 \mathrm{~min}$ inkubiert, die Äquilibrierung geschieht wahrscheinlich in wesentlich kürzerer Zeit $[19,52]$. Bei den ersten Untersuchrungen wurde ${ }^{14} \mathrm{C}-4$-Cortisol verwendet, und zwar pro Ansatz 0,083 $\mu \mathrm{Ci}=$ etwa $0,1 \mu \mathrm{g}$ Cortisol. Später waren echte Traceruntersuchungen mit einem ${ }^{3} \mathrm{H}-1,2$-Cortisol höherer spezifischer Aktivität möglich, von dem pro Ansatz 
$0,05 \mu \mathrm{Ci}=$ etwa $0,009 \mu \mathrm{g}$ Cortisol eingesetzt wurden, was einer Erhöhung des Plasmacortisols um 0,3 $\mu \mathrm{g}$ \% im Ansatz entsprach. ${ }^{14} \mathrm{C}-4$-Cortisol (spez. Aktivität $30,4 \mathrm{mCi} / \mathrm{mM}$ ) in einem Benzol-Äthanol-Gemisch von $9: 1$, bzw. ${ }^{3} \mathrm{H}-1,2$-Cortisol in Benzol gelöst (spez. Aktivität $2,0 \mathrm{Ci} / \mathrm{mM}$ ) wurden von der Fa. Radio-Chemical-Center Amersham, England, bezogen. Die Reinheit war vom Hersteller papier. und dünnschichtehromatographisch geprüft, die Substanzen wurden ohne weitere Kontrolle verwendet. Standardlösungen wurden bei $+4^{\circ} \mathrm{C}$ aufbewahrt.

3. Dextrangelfiltration: Sie wurde nach den Angaben von FLoDTr [23] mit geringen Modifikationen durchgeführt [52, 77]: 4 g Dextrangel (Sephadex G 10, Fa. Pharmacia Uppsala, Schweden) pro Säule $(h=23 \mathrm{~cm}, d=0,8 \mathrm{~cm})$, Durchflußgeschwindigkeit $0,6-0,7 \mathrm{ml} / \mathrm{min}$ ). $1 \mathrm{ml}$ des Inkubationsgemisches wurde nach sorgfaltigem Mischen mit einer Pipette vorsichtig, ohne die Oberfläche des Gelbettes aufzuwirbeln, auf die Säule gebracht. Nach Einsinken der Probe wurden $2 \mathrm{mal}$ je $1 \mathrm{ml} \mathrm{0,01} \mathrm{M} \mathrm{Natriumphosphatpuffer} \mathrm{pH} \mathrm{7,4} \mathrm{aufgetra-}$ gen und dabei die Säulenwand abgespült. Anschließend wurde die Säule luftdicht mit einem Puffervorratsgefä $\beta$ verbunden und unter einem Filtrationsdruck von etwa $1 \mathrm{~m}$ Wassersäule eluiert, das Sammeln des Eluates begann sofort. Doppelbestimmungen wurden für jede Inkubation durchgeführt.

Um einen Utberblick über die Verteilung von proteingebundenem und sog. freiem Cortisol zu erhalten, wurden die Eluate zunächst mit einem automatischen Fraktionssammler (Chromatopart der Fa. Bender \& Hobein, München) in $2 \mathrm{ml}$ Portionen aufgetrennt. Bei diesen Vorversuchen wurde mit dem Sammeln unmittelbar nach Einsinken des Plasma ins Gelbett begonnen. Da die Elution des nicht proteingebundenen Cortisols mit dem Phosphatpuffer nur langsam erfolgt, wurde dieser Vorgang dureh Nachwasehen mit $2 \mathrm{ml}$ Normalserum beschleunigt. Nachdem auf diese Weise die Volumina zur Elution von proteingebundenem und sog. freiem Cortisol ermittelt waren, wurde routinemäßig die einfachere BatchTechnik angewendet mit den Gesamtvolumina I und II von $8 \mathrm{bzw} .10 \mathrm{ml}$ (Abb. 1a). Parallel wurde in einigen Versuchen der Proteingehalt der Eluate nach LowRY [38] bestimmt (Abb. 1b). Bei Inkubation von Cortisol mit physiologischer $\mathrm{NaCl}$ und anschlieBender Gelfiltration fand sich in den ersten $10 \mathrm{ml}$ Eluat keine Radioaktivität.

4. Eine direkte Messung der Radioaktivität in den einzelnen Eluaten vor allem bei der Chromatoparttechnik war durch den unterschiedlichen Proteingehalt, den hohen Wassergehalt und die geringe Radioaktivität der einzelnen Proben zunächst nicht möglich, daher wurde das Cortisol aus den Fraktionen mit Dichlormethan im Verhältnis $1: 3$ in einem Rotor bei $40 \mathrm{U} / \mathrm{min} 20 \mathrm{~min}$ lang extrahiert. Nach Absaugen des Utberstandes wurden $10 \mathrm{ml}$ des verbleibenden Dichlormethanextraktes in ein Zählprobenfläschchen der Fa. Packard Instrument GmbH, Frankfurt, abgefüllt und im Wasserbad bei etwa $40^{\circ} \mathrm{C}$ unter Vakuum zur Trockene eingeengt. Der Rückstand wurde in $15 \mathrm{ml}$ Szintillationsgemisch [bestehend aus 5 Liter Toluol p.A., $15 \mathrm{~g}$ 2,5-Diphenyloxazol (PPO) und $3 \mathrm{~g}$ 1,4-2 (4-Methyl-5-Phenyloxazolyl)-Benzol (POPOP), Fa. Pakkard Instrument] gelöst und im Tricarb-liquid-Szintillationsspektrometer, Modell 3003, der Fa. Packard-Instrument gezählt. Die Ausbeute dieser Methode betrug durchschnittlich $94,5 \%$ der aufgetragenen Aktivität, sog. freies und proteingebundenes Cortisol sind in \% der wiedergefundenen Aktivität angegeben. Die Zählausbeute betrug ca, $30 \%$ für ${ }^{3} \mathrm{H}$-Toluol.

5. Bestimmung der 11-OHCS: Sie erfolgte mit geringer Modifikation nach den Angaben von Matrisalex [40]: Der Dichlormethan-Extrakt wurde mit $1 \mathrm{~N} \mathrm{NaOH}$ einmal gewaschen. Cortisol-reinst zur Herstellung von Eichlösungen für die fluorimetrisehe Bestimmung der 11-OHCS wurde von der Firma Schering zur Verfügung gestellt. Das Fluorescenzreagens bestand aus 3 Teilen absolutem Alkohol und 7 Teilen konzentrierter $\mathrm{H}_{2} \mathrm{SO}_{4}[40]$.

6. Statistische Berechnung: Die Signifikanz der Ergebnisse wurde mit dem $t$-Test geprüft [85].

\section{Ergebnisse}

1. Vorversuche. Bei Zusatz von ${ }^{14} \mathrm{C}-4$-Cortisol in zunehmender Menge fand sich ein steigender Prozentsatz von sog. freiem Cortisol infolge Absättigung der Transcortinbindungskapazität (Abb.2a). Für Rou* tinebestimmungen wurde daher die kleinste noch zur radioaktiven Messung geeignete Menge von 3,3 $\mu \mathrm{g}$

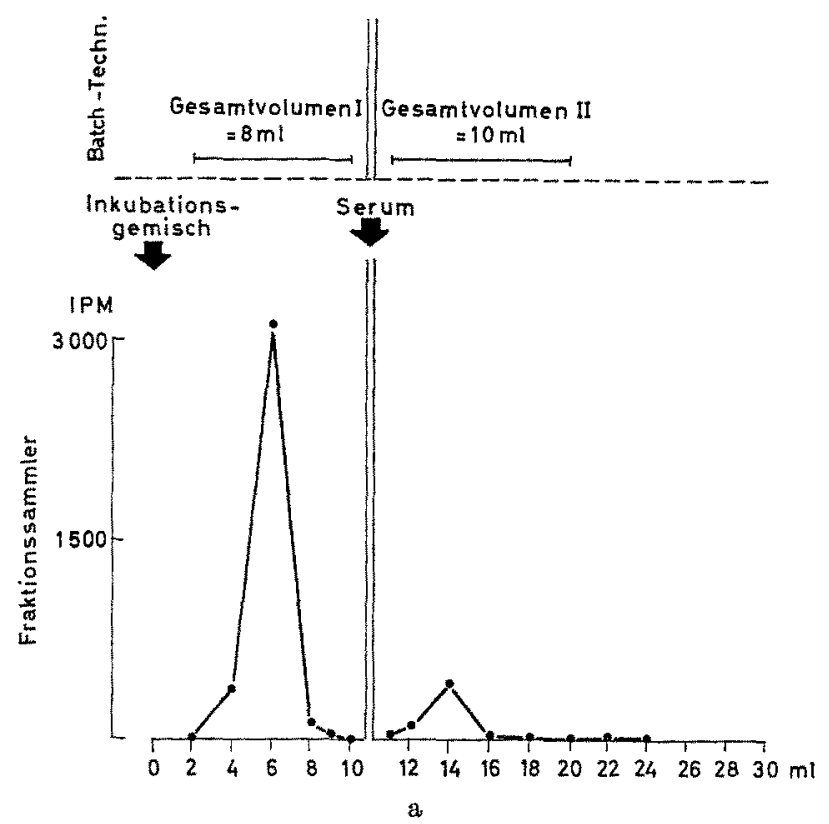

INKUBATION MIT ${ }^{3} \mathrm{H}-1.2$ - CORTISOL

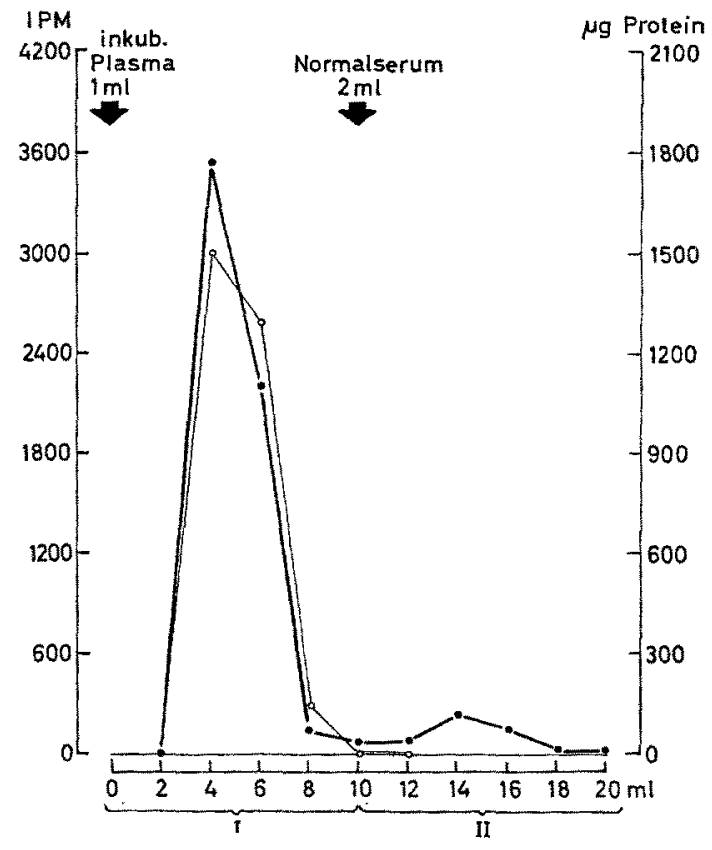

b

Abb. 1a u. b. Trennung von proteingebundenem und sog. freiem Plasmacortisol mittels Dextrangelfiltration. a Schematische Aufzeichnung des fraktionierten Sammelns (unten) bzw. der Batch-Technik (oben). b Zum Vergleich Darstellung eines Filtrationsversuches. Parallel zur Radioaktivitätsmessung (- - Bestimmung des Proteingehaltes der einzelnen Proben nach Lowry $(0-0)$, soweit die Proteine ans dem Inkubationsgemisch stammten. Unten $(I, I I)$ sind die Sammelvolumina bei der Batch-Technik angedeutet

pro $100 \mathrm{ml}$ Ansatz gewählt, die keine Sättigung der Bindungskapazität bewirkt [49]. Beim ${ }^{3}$ H-1,2-Cortisol mit erheblich höherer spezifischer Aktivität konnten wesentlich geringere Mengen an. Cortisol zugesetzt werden (Abb. $2 \mathrm{~b}$ ) [77].

Um den Einfluß der Dextrangelmenge auf das Verhältnis an proteingebundenem und sog. freiem Plasmacortisol zu untersuchen, wurde das gleiche Inkubationsgemisch auf Säulen aufgetragen, deren Gelbett 


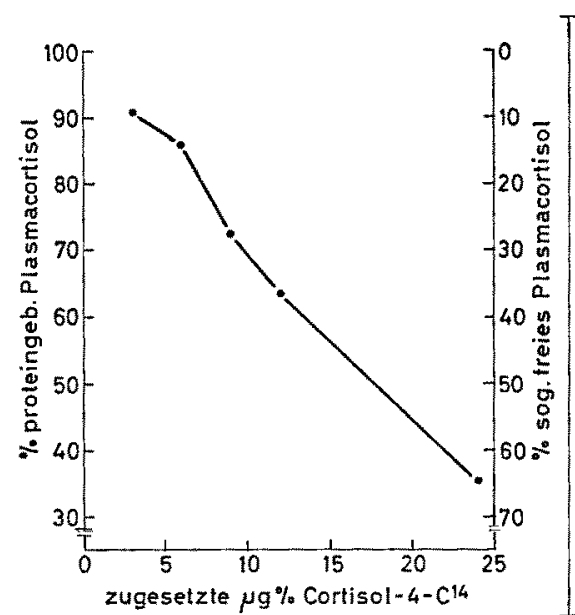

a

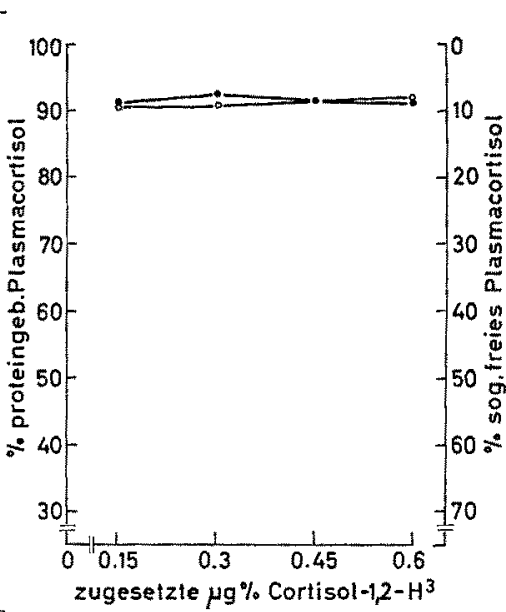

$\mathrm{b}$

Abb. 2 a a. b. Einfluß der im Inkubationsansatz zugesetzten Menge von radioaktivem Cortisol auf die Proteinbindungsverhältnisse. a Zunahmo von sog. freiem Cortisol bei steigender Menge von ${ }^{14} \mathrm{C}-4$-Cortisol geringer spezifischer Aktivität infolge Uberschreitung der Cortisolbindungskapazität. RoutinemäBig wurden $3,3 \mu \mathrm{g}$ Cortisol pro $100 \mathrm{ml}$ Inkubationsgemisch zugegeben. b Zusatz von ${ }^{3} \mathrm{H}-1,2$-Cortisol höherer spezifischer Aktivität: Keine Veränderung der Proteinbindung im untersuchten Bereich (2 Versuche). Routinemäßig wurden $0,3 \mu g$ pro $100 \mathrm{ml}$ zugesetzt

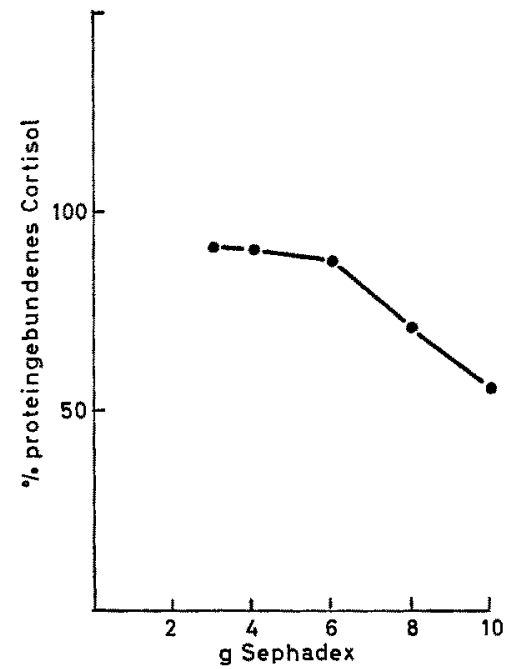

Abb. 3. Abhängigkeit des Anteils von proteingebundenem bzw. sog. freiem Cortisol von der Menge an Sephadex-Gel. Bei den Routinebestimmungen Füllung der Säulen mit je 4 g Sephadex G-10

3-10 g Trockensubstanz Sephadex-G-10 entsprach (Abb. 3). Vor allem oberhalb von $6 \mathrm{~g}$ fand sich eine deutliche Verschiebung der Bindungsverhältnisse zugunsten des sog. freien Plasmacortisols. Zur Überprüfung der Reproduzierbarkeit wurde ein Mischplasma (11-OHCS $=21 \mu \mathrm{g}-\%)$ nach der angegebenen Methode an einem Tag 10fach untersucht, es ergab sich ein Mittelwert des proteingebundenen Cortisols von 91,5土 $0,63 \%(\bar{x} \pm s)$, der Variationskoeffizient war $V K=$ $0,69 \%$. Die wiederholte Untersuchung des Plasma eines gesunden Probanden (11-OHCS $=13 \mu \mathrm{g}$ - \%) über einen Zeitraum von 7 Monaten nach mehrfachem Auftauen und Wiedereinfrieren $[47,63]$ hatte folgendes Ergebnis: Proteingebundener Anteil $=91,7 \pm 1,02 \%$, sog. freier Anteil $=8,3 \pm 1,02(\bar{x} \pm s), N=5$.

2. Proteinbindungsverhältnisse bei Gesunden. Untersucht wurden je 10 Angehörige des Personals der Klinik sowie 10 Rekonvaleszenten ohne endokrine oder Stoffwechselerkrankung (Abb.5). Die 11-OHCS betrugen im Mittel 12,2 $\pm 3,2(\bar{x} \pm s)$, Normalbereich:
$4,5-20,9 \mu g-\%(N=42)$. Für den proteingebundenen Anteil des Plasmacortisols ergab sich ein Mittelwert von $89,7 \pm 2,45 \%$, für den sog. freien Anteil 10,3 2,45\%. Die entsprechenden Normalbereiche exstrecken sich also von $84,8-94,6$, bzw. von $5,4-15,2 \%(\bar{x} \pm 2 s$, $N=20$ ).

3. Veränderungen der Cortisolbindungsverhältnisse im Plasma unter ACTH-Infusion. Unter den Bedin. gungen eines routinemäßigen ACTH-Belastungstestes (25 IE ACTH bzw. $0,25 \mathrm{mg}$ Synacthen (B) im Dauertropf von $9.00-13.00 \mathrm{Uhr}$ an 2 aufeinanderfolgenden Tagen) wurden die 11-OHCS-Spiegel und die Bindung des Plasmacortisols an Proteine untersucht. Über die Brauchbarkeit dieses Verfahrens zur Diagnose der Nebennierenrindeninsuffizienz und des Cushing-Syndroms wurde schon berichtet $[30,51]$. Die Multiplikation des 11-OHCS-Spiegels ( $\mu \mathrm{g}-\%)$ mit dem Prozentsatz von proteingebundenem bzw. sog. freiem Cortisol erlaubt eine annähernde Berechnung der absoluten Mengen von gebundenem bzw. sog. freiem Cortisol (Abb. 4). Es wird deutlich, daß unter der ACTHBelastung das proteingebundene Plasmacortisol nur wenig zunahm; der Anstieg des Gesamtplasmacortisols (11-OHCS) ist praktisch ausschließlich auf die Zunahme von ungebundenem Cortisol zurückzuführen $[51,52]$.

4. Proteinbindung bei Nebennierenrindeninsuffizienz. 17 Patienten mit primärer Nebennierenrindeninsuffizienz oder Zustand nach beiderseitiger totaler Adrenalektomio wurden z. T. mehrfach untersucht $(N=24)$. Für die 11-OHCS ergab sich ein Mittelwert von $5,4 \pm 2,7 \mu \mathrm{g}-\%(\bar{x} \pm s)$, der niedriger als der Mittelwert des Normalkollektivs $(p<0,0005)$ ist, jedoch noch im Normalbereich liegt. Der relativ hohe Wert der 11-OHCS bei Patienten ohne nachweisbare Nebennierenrindenfunktion beruht auf der unspezifischen Basisfluorescenz, die bei der fluorimetrischen Bestimmung auftritt $[40,46]$. Das Plasma für diese Untersuchungen wurde 24 Std nach Absetzen einer Cortisolsubstitution entnommen, zu dieser Zeit ist sicher kein exogen zugeführtes Cortisol mehr im Plasma vorhanden [69]. In den gleichen Plasmen fand sich ein im Mittel deutlich erhöhter Anteil des proteingebun- 


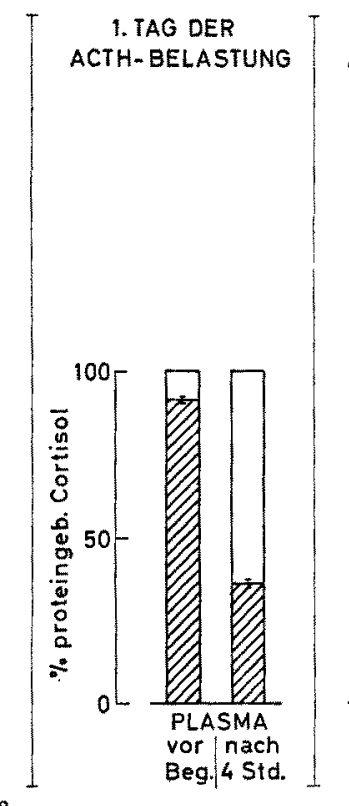

a
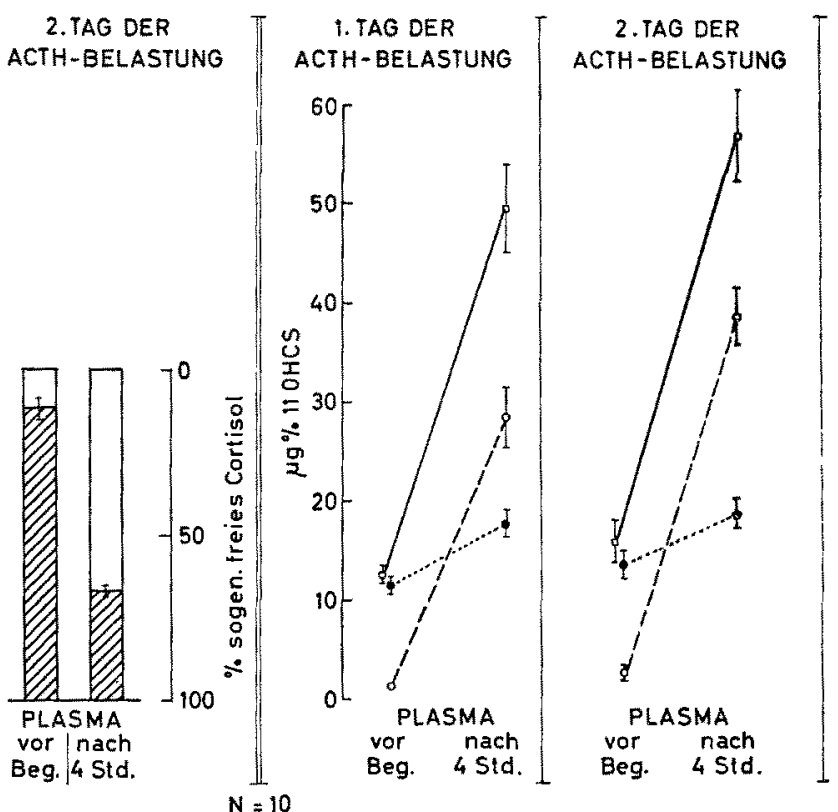

$\mathrm{b}$

Abb. 4a a. b. Veränderung der Proteinbindung des Plasma-Cortisols $\left(\bar{x}_{ \pm} s\right)$ unter vierstündiger Dauerinfusion von $0,25 \mathrm{mg}$ $\mathrm{ACTH}$ an 2 aufeinanderfolgenden Tagen. a Prozentuale Zunahme des sog. freien (weiß) und entsprechende Abnahme des proteingebundenen Cortisols (schraffiert). b 11-OHCS-Spiegel ( $(-\square)$ und Absolutwerte des sog. freien $(0---0)$ und des proteingebundenen Cortisols ( $0 \ldots . . .-O)$ in $\mu g$. \%. Der Anstieg des Gesamtcortisols beruht hauptsächlich auf einer Zunahme des nicht proteingebundenen Anteils

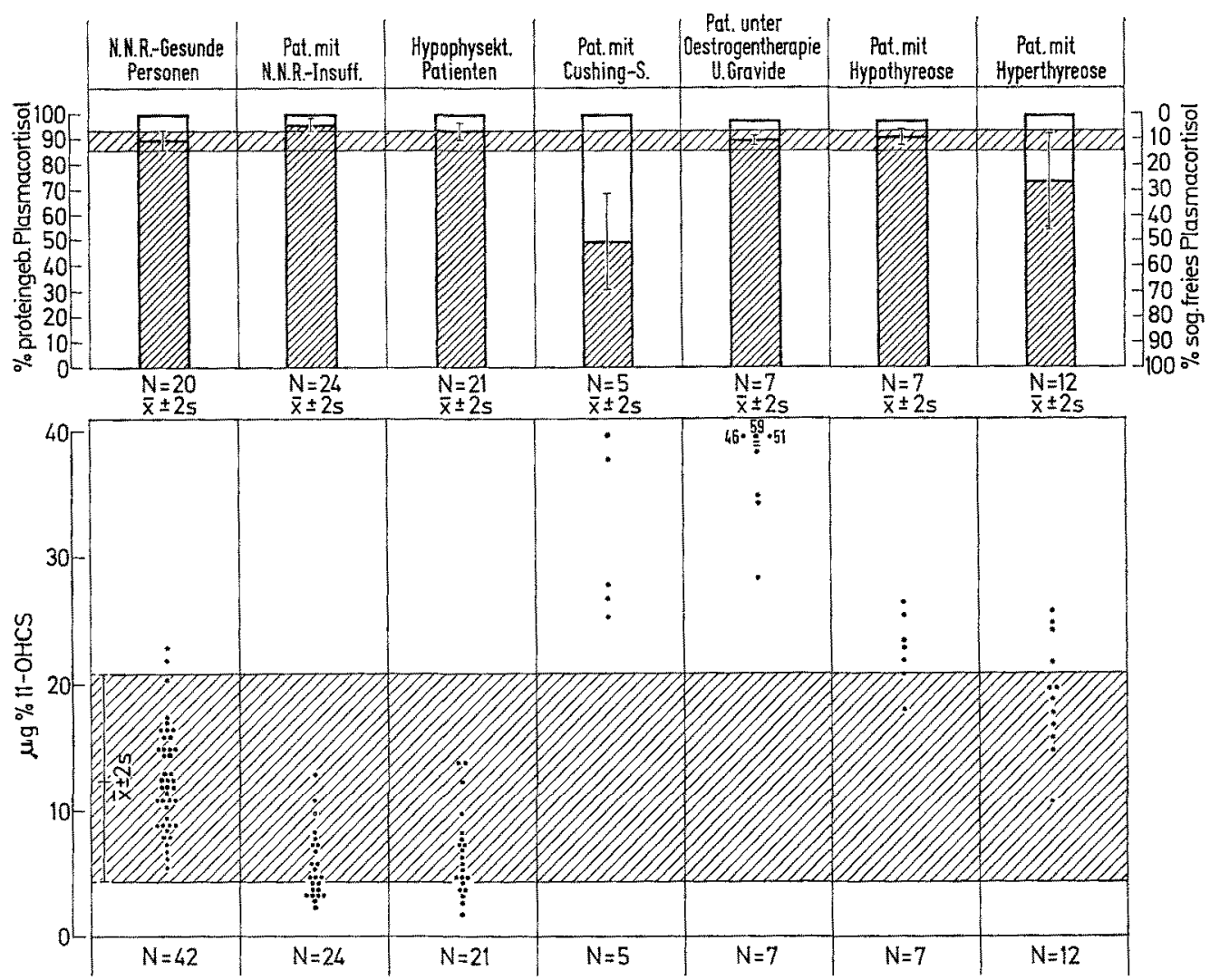

Abb. 5. Plasmaproteinbindung von Cortisol und 11-OHCS-Werte bei Störungen der NNR-Funktion. Vergleich der mittels Dextrangelfiltration untersuchten Proteinbindungsverhältnisse des Plasmacortisols (oben) mit den fluorimetrisch bestimmten Gesamtcortisolspiegeln im Plasma (unten, Einzelwerte). Normalbereiche jeweils schraffiert. Zahl der Fälle $=N$. Im oberen Teil der Abbildung Darstellung der Cortisolbindung in \% durch Säulen, gepunktet ist der Prozentsatz des gebundenen, weiß der Prozensatz des sog. freien Plasmacortisols angegeben

denen Cortisols von $96,1 \pm 1,34 \%$ bei entsprechend niedrigem Anteil des sog. freien Plasmacortisols von $3,9 \pm 1,34 \%$ (Abb. 5). Betrachtet man die 10 Patienten mit Morbus Addison, bei denen vor allem im Falle einer Restfunktion der Nebennierenrinde die
Labordiagnose schwierig sein kann, gesondert, so zeigt sich, daß ihre Werte des proteingebundenen Cortisols mit 96,8 $\pm 1,27 \%(\bar{x} \pm s, N=11)$, bei 11-OHCS-Spiogeln von $6,0 \pm 3,7 \mu \mathrm{g}-\%$, von denen der Normalpersonen praktisch vollständig getrennt sind. 
Tabelle 1. Ergebnisse von 17 hypophysektomierten Patienten, z. T. mehrfach bestimmt $(N=21)$

\begin{tabular}{|c|c|c|c|c|c|c|c|c|}
\hline \multirow[t]{2}{*}{ Patient } & \multirow[t]{2}{*}{ Diagnose } & \multirow{2}{*}{$\begin{array}{l}\text { Zeit nach } \\
\text { Hypophys- } \\
\text { ektomie }\end{array}$} & \multicolumn{4}{|c|}{ 11-Hydroxycorticosteroide ( $\mu \mathrm{g} . \%)$} & \multicolumn{2}{|c|}{ Plasmacortisol } \\
\hline & & & Plasma A & Plasma B & Plasma $\mathrm{C}$ & Plasma D & $\begin{array}{l}\text { \% prot.- } \\
\text { geb. }\end{array}$ & $\begin{array}{l}\% \text { sog. } \\
\text { freies }\end{array}$ \\
\hline A. W., $0^{\star}$ & chromophobes Adenom & 5 Monate & 8,5 & 26,0 & 15,0 & 37,0 & 94,9 & 5,1 \\
\hline W. E., O & chromophobes Adenom & - & 5,5 & 27,0 & 14,0 & 24,0 & 93,5 & 6,5 \\
\hline W. E., $\overrightarrow{O^{\star}}$ & chromophobes Adenom & - & 14,0 & 42,5 & 17,0 & 54,5 & 93,2 & 6,8 \\
\hline S. M., & chromophobes Adenom & 5 Monate & 3,5 & & & & 96,3 & 3,7 \\
\hline S. M., ô & chromophobes Adenom & 1 Monat & 6,5 & 16,5 & 8,0 & 32,0 & 93,9 & 6,1 \\
\hline S. T., & Adenom vom Mischtyp & 9 Monate & 3,0 & 25,5 & 4,0 & 34,0 & 94,4 & 5,6 \\
\hline S. I., & Adenom vom Mischtyp & 12 Monate & 5,0 & & & & 95,6 & 4,4 \\
\hline K. J., O & Adenom vom Mischtyp & 1 Monat & 5,0 & 15,0 & 10,0 & 38,0 & 95,7 & 4,3 \\
\hline H. J., O & Adenom vom Mischtyp & il Monate & 5,0 & 16,5 & 5,0 & 23,0 & 92,6 & 7,4 \\
\hline J. K., $q$ & Adenom vom Mischtyp & 3 Monate & 14,0 & 50,0 & 17,0 & 56,5 & 89,9 & 10,1 \\
\hline F. F., ô & Adenom vom Mischtyp & 3 Monate & 2,0 & 14,0 & 4,5 & 22,0 & 96,2 & 3,8 \\
\hline S. A., & Adenom vom Mischtyp & 1 Monat & 10,0 & 42,5 & 10,5 & 52,0 & 96,1 & 3,9 \\
\hline S. J., & Zustand nach H. E. & 6 Jahre & 12,5 & 56,0 & & & 91,3 & 8,7 \\
\hline S. I., & Craniopharyngeom & 12 Monate & 7,5 & 7,0 & 6,0 & 11,0 & 94,6 & 5,4 \\
\hline B. J., & Zustand nach H. E. & 11 Jahre & 4,0 & 14,5 & 9,0 & 21,5 & 94,3 & 5,7 \\
\hline M. J., $\widehat{0}$ & para- und susprasell. Chondrom & 2 Monate & 4,0 & 11,0 & 6,5 & 23,5 & 94,4 & 5,6 \\
\hline M. J., oै & para- und suprasell. Chondrom & 3 Monate & 6,0 & 14,0 & 6,0 & 28,0 & 95,4 & 4,6 \\
\hline S. M., O & Zustand nach H. E. & 9 Monate & 7,5 & 23,5 & 20,5 & 43,5 & 94,6 & 5,4 \\
\hline S. M., & chromophobes Adenom & 15 Monate & 4,5 & & & & 97,7 & 2,3 \\
\hline S. H., A & chromophobes Adenom & 5 Monate & 8,0 & & & & 94,6 & $\mathbf{5 , 4}$ \\
\hline G. B., $\stackrel{9}{+}$ & Sheehan-Syndrom & - & 7,0 & & & & 95,7 & 4,3 \\
\hline rmal & Gest & - & $5,5-19$, & $24,3-74$ & $3,2-38$ & $31,7-80,9$ & $84,8-94,6$ & $5,4-15$, \\
\hline
\end{tabular}

1. Tag der ACTH-Belastung: Plasma A: 9 Uhr vor ACTH; Plasma B: 13 Uhr nach 0,25 mg Synacthen® pro 4 Std i.v.

2. Tag der ACTH-Belastung: Plasma $C$ und D wie 1.Tag. Zum Vergleich sind die Normalbereiche Gesunder $(\bar{x} \pm 2 s)$ angegeben.

Bei 10 Patienten mit Nebennierenrindeninsuffizienz (4 Addisonkranke, 6 Totaladrenalektomierte) wurde zusätzlich die Proteinbindung im Plasma untersucht, das 2 Std nach einer oral verabreichten üblichen Substitutionsdosis von $15 \mathrm{mg}$ Cortisol um $9.00 \mathrm{Uhr}$ entnommen wurde. $\mathrm{Zu}$ dieser Zeit ist der maximale Plasmaspiegel zu erwarten $[56,69]$. Während bei diesen Patienten im Plasma 24 Std nach Absetzen von Cortisol 11-OHCS-Spiegel von 5,3 $\pm 2,5 \mu \mathrm{g}-\%$ sowie $95,7 \%$ proteingebundenes bzw. $4,3 \%$ sog. freies Plasmacortisol gemessen wurden, fanden sich 2 Std nach $15 \mathrm{mg}$ Hydrocortison ${ }^{\circledR}$.Hoechst p.o. im Mittel $26,9 \mu \mathrm{g}-\%$ 11-OHCS und $77,8 \%$ proteingebundenes Cortisol. Der Absolutwert des proteingebundenen Cortisols (s. o.) von $20,9 \mu \mathrm{g}$ - \% liegt unterhalb der in der Literatur angegebenen Transcortinbindungskapazität [49].

5. Patienten mit Hypophysentumoren. Bei 9 Patienten mit Hypophysentumoren bzw. parasellären Tumoren wurden vor Behandlung die 11-OHCS-Spiegel und die Proteinbindung im Plasma bestimmt, außerdem ein i.v. ACTH-Test durchgeführt. Die 11-OHCSSpiegel lagen bis auf einen leicht erhöhten Wert im Normalbereich.

Nur bei einem Patienten, der mit 6,5 $\mu \mathrm{g}$ \% 11-0HCS den niedrigsten Wert dieser Gruppe aufwies, wurde eine vermehrte Proteinbindung von 95,1\% festgestellt. Dieser Patient ließ auch beim ACTH-Belastungstest eine dentliche sekundäre Nebennierenrindeninsuffizienz erkennen. Diese Ergebnisse entsprechen der klinischen Eirfahrung, $\mathrm{da} B$ die adrenocorticotrope Funktion bei Hypophysentumoren als letzte ausfällt.

Bei zwei weiteren Patienten, bei denen das Ergebnis des ACTH-Tests den Verdacht auf sekundäre Nebennierenrindeninsuffizienz erweckte, konnte keine Veränderung der Proteinbindungsverhältnisse gefunden werden. $Z$ wei dieser 9 Patienten konnten auch nach operativer Hypophysektomie untersucht werden. Bei beiden fand sich ein Absinken des 11-OHCSSpiegels und ein Anstieg des proteingebundenen Cortisolanteils.

Bei 6 Patienten mit einem Hypophysenadenom, die klinisch die deutlichen Zeichen einer Akromegalie aufwiesen und von denen einer röntgen-vorbestrahlt war, fanden sich normale 11-OHCS- und normale Proteinbindungsverhältnisse. Ubereinstimmend fanden Winkelmand u. Mitarb. bei akromegalen Patienten $[62,84]$ zwar eine vermehrte Sekretionsrate von Cortisol, aber normale 9.00-Uhr-Plasmawerte der 11-OHCS. Vier dieser Patienten wurden auch nach Implantation von ${ }^{90}$ Yttrium in die Sella untersucht. Zweimal wurde ein Absinken des Gesamtplasmacortisols und eine Zunahme der Proteinbindung festgestellt; bei diesen beiden Patienten war es als Folge des Eingriffes zu einer Blutung gekommen, wie die neurologische Symptomatik und der Liquorbefund zeigten. Die beiden anderen Patienten wiesen dagegen sogar einen leichten Anstieg des Gesamtplasmacortisols ohne wesentliche Veränderung der Proteinbindung auf. HaRToG u. Mitarb. [27] haben über 22 Patienten mit Akromegalie berichtet, die mit einer bzw. zwei Implantationen von ${ }^{198} \mathrm{Au}$ bzw. ${ }^{90} \mathrm{Y}$ behandelt wurden. Von diesen benötigten 9 eine Substitutionstherapie mit Corticosteroiden.

6. Hypophysektomierte Patienten. Bei 17 Patienten, die wegen verschiedenartiger Hypophysentumoren bzw, para- oder suprasellärer Tumoren unter versuchter Schonung des Hypophysenvorderlappens operiert wurden, und bei einer Patientin mit einem SheehanSyndrom wurden z. T. zweimal fluorimetrisch die 11-OHCS im Plasma sowie der Prozentsatz proteingebundenen bzw. sog. freien Cortisols bestimmt ( $\mathrm{Ta}$ belle 1).

Nur bei 5 Patienten lagen die 11-OHCS-Spiegel (Plasma A) unterhalb des Normalbereiches (Abb.5). Dagegen fand sich in 8 Fällen eine Vermehrung des proteingebundenen Plasmaoortisols über den Normalbereich hinaus als Ausdruck der sekundären Nebennierenrindeninsuffizienz (Tabelle 1, 2). Bei weiteren 6 Fällen lag der gebundene Anteil im oberen Normalbereich, nur in den übrigen 3 Fällen war er unauffällig. Der Mittelwert von $94,5 \pm 1,76(\bar{x} \pm \delta)$ ist gegenüber dem Normalwert von $89,7 \%$ signifikant erhöht $(p<0,0005)$. Von 16 ACTH-Belastungen bei 14 Patienten erbrachte dieser Test in 6 Fällen (S. M., H. J., F. F., S. L., B. J. und M. J.) die Diagnose einer sekundären NNR-Insuffizienz. Bei 3 Patienten fiel die ACTH-Belastung normal aus, in 5 Fällen war das Eirgebnis nicht eindeutig (Tabelle 1, 2). Nur bei einem der Patienten mit normalem ACTH-Test wurde eine vermehrte Proteinbindong festgestellt, bei den 5 Patienten mit nur z.T. verringertem Anstieg der 11-OHCS-Spiegel unter ACTH. 
Tabelle 2. Zustand nach Hypophyseltomie

\begin{tabular}{|c|c|c|c|}
\hline & \multicolumn{3}{|c|}{$\begin{array}{l}\text { Diagnose einer sekundären NNR- } \\
\text { Insuffizienz durch }\end{array}$} \\
\hline & \multirow{2}{*}{$\begin{array}{l}\text { ACTH- } \\
\text { Belastung } \\
\text { (Patienten) }\end{array}$} & \multicolumn{2}{|c|}{ Cortisol-Proteinbindung } \\
\hline & & Patienten & $\begin{array}{l}\text { prot.-geb. } \\
\text { Cortisol }\end{array}$ \\
\hline Gesichert & 6 & 8 & $>94,6 \%$ \\
\hline Fraglich & 5 & 7 & $92,1-94,6 \%$ \\
\hline Nicht nachweisbar & 3 & 2 & $<92,1 \%$ \\
\hline Gesamt & $N=14$ & $N=17$ & $\begin{array}{l}\text { Normal- } \\
\text { bereich } \\
84,8-94,6 \%\end{array}$ \\
\hline
\end{tabular}

Belastung lag das proteingebundene Cortisol im obersten Normalbereich.

Die diagnostische Aussagekraft der aufwendigen ACTH-Belastung ist somit nicht größer, als die der einfachen Bestimmung der Cortisolbindung im Plasma.

7. Cushing Syndrom. Untersucht wurden 3 Patienten, deren Erkrankung auf einer beiderseitigen Nebennierenrindenhyperplasie beruhte, 2 davon wurden nach einseitiger Adrenalektomie kontrolliert. Die Ergebnisse sind in Tabelle 3 zusammengefaßt. Proteingebundenes Cortisol und 11-OHCS der Patienten mit Cushing-Syndrom lagen weit auBerhalb der Normalbereiche, $p<0,0005$ (Abb. 5).

Tabelle 3. Patienten mit Cushing-Syndrom

\begin{tabular}{|c|c|c|c|c|}
\hline \multirow[t]{2}{*}{ Patient } & \multirow[t]{2}{*}{ Zustand } & \multirow{2}{*}{$\begin{array}{l}11-\mathrm{OHCS} \\
(\mu \mathrm{g}-\%)\end{array}$} & \multicolumn{2}{|c|}{ Plasmacortisol } \\
\hline & & & $\begin{array}{l}\% \text { prot.- } \\
\text { geb. }\end{array}$ & $\begin{array}{l}\% \text { sog. } \\
\text { freies }\end{array}$ \\
\hline E. T., & q vor Adrenalektomie & 40,0 & 38,4 & 61,6 \\
\hline E. T., & $\begin{array}{l}\text { nach einseitiger } \\
\text { Adrenalektomie }\end{array}$ & 38,0 & 44,5 & 55,5 \\
\hline K. J., & $\delta$ vor Adrenalektomie & 25,5 & 46,9 & 53,1 \\
\hline K. J., & $\begin{array}{l}\text { onach einseitiger } \\
\text { Adrenalektomie }\end{array}$ & 28,0 & 55,5 & 44,5 \\
\hline S. G., & I vor Adrenalektomie & 27,0 & 65,1 & 34,9 \\
\hline $\bar{x}$ & & 31,7 & 50,1 & 49,9 \\
\hline
\end{tabular}

Bei einer Patientin mit dem klinischen Verdacht auf ein paraneoplastisches Cushing-Syndrom [72] ergab die Bestimmung der 11-OHCS im Plasma, das um 9.00 Uhr entnommen war, $136 \mu \mathrm{g}-\%$, im 18.00 Uhr-Plasma $128 \mu \mathrm{g}-\%$. Diese extrem hohen Werte waren durch eine Therapie mit Spirolacton (Aldactone $\left.{ }^{(}\right)$) verursacht, das eine erhebliche Fluorescenz bei der angewandten Methode ergibt [46, 86]. Die 11-OHCSBestimmung war also in diesem Falle nicht $\mathrm{zu}$ verwerten. Daher wurde die Proteinbindung von Cortisol untersucht. Dabei fand sich im 9.00 Uhr-Plasma ein Anteil des proteingebundenen Cortisols von $71,5 \%$ und des sog. freien von $28,5 \%$, im 18.00 Uhr-Plasma von 67,8 bzw. 32,2\%. Die Autopsie ergab ein entdifferenziertes Adenocarcinom des Pankreas mit ausgedehnter Metastasierung in die Leber. Die Diagnose ektopisches ACTH-Syndrom konnte durch die Bestimmung des ACTH im Plasma und im Tumorgewebe bestätigt werden [72]. Bei zwei weiteren Patienten, die unter einer Aldaclone(\$) Therapie standen und 11-OHCS-Werte im 9.00 Uhr-Plasma von $410 \mathrm{bzw} .207 \mu \mathrm{g}$. \% aufwiesen, betrug das proteingebundene Cortisol 92,3 bzw. 91,3, das sog. freie 7,7 bzw. $8,7 \%$, also normale Werte.

8. Einfluß von Gravidität und Oestrogenbehandlung. In der Gravidität und unter einer Behandlung mit Oestrogenen werden bekanntlich erhöhte Plasmaspiegel an Gesamtcortisol gefunden, die denen bei einem Cushing-Syndrom entsprechen können. Die Brauch- barkeit dieser Methode zur Abklärung solcher hohen Plasmacortisolspiegel zeigte sich bei 3 oestrogenbehandelten Frauen mit 11-OHCS-Werten zwischen 28,5 und $46 \mu \mathrm{g}-\%$, die im Gegensatz zu den CushingKranken einen hochnormalen proteingebundenen Prozentsatz von $92-93,8 \%$ aufwiesen. Bei 4 graviden Patientinnen im letzten Monat der Schwangerschaft wurden 11-OHCS-Werte zwischen 38,5 und $59 \mu \mathrm{g}-\%$ gemessen, auch hier fand sich ein normaler bzw. eher hoher Anteil von proteingebundenem Cortisol zwischen 90,5 und $92,8 \%(\mathrm{Abb} .5)^{2}$.

9. Hyperthyreosen. Bei den 12 untersuchten Patienten stützte sich die Diagnose auf die klinischen Befunde, die PB ${ }^{127}$ T-Werte und den Radiojodtest [28]. Bei diesen Patienten fanden sich fluorimetrisch gemessene Plasmacortisolspiegel im oberen Normalbereich oder darüber (Abb. 5$)$, der Mittelwert $\bar{x} \pm s=$ $19,5 \pm 4,45 \mu \mathrm{g}$ - \% war signifikant gegenüber dem Mittelwert des Normalkollektivs erhöht $(p<0,0005)$. Die Proteinbindung war signifikant $(p<0,0025)$ verändert im Sinne einer Zunahme des sog. freien Cortisols auf $25,9 \%$, obwohl bei den gemessenen Gesamtcortisolspiegeln (11-OHCS) bis $26,0 \mu \mathrm{g}$ - \% die Bindungskapazität des Transcortins nicht abgesättigt ist [49]. Teilt man nämlich das Gesamtcortisol nach den prozentualen Bindungsverhältnissen, so errechnet sich im Mittel ein Gehalt von 14,4 $\mu g^{-} \%$ gebundenem (normal $\left.11,4 \mu g_{-} \%\right)$ und von $5,1 \mu g$. \% sog. freiem Cortisol (normal 1,3 $\mu \mathrm{g}-\%$ ). Bei der Hyperthyreose findet sich also eine Zunahme des Gesamtcortisols im Plasma und diese Erhöhung ist vornehmlich durch eine unproportional starke Vermehrung des sog. freien Cortisols bedingt $[30]$.

10. Hypothyreosen. Bei den 7 untersuchten Fällen, die ein im Mittel ebenfalls erhöhtes Plasmacortisol von $19,5 \mu \mathrm{g}-\%$ aufwiesen, lag der proteingebundene Anteil $(\tilde{x}=93,4 \%)$ stets im oberen Normalbereich (Abb. 5), einmal sogar darüber. Die Berechnung der Absolutwerte des Plasmacortisols ergab 18,2 $\mu \mathrm{g}-\%$ proteingebundenes und $1,3 \mu \mathrm{g}-\%$ sog. freies Cortisol, d. h. in diesem Falle ist die Zunahme des Gesamtcortisols nur auf eine vermehrte Proteinbindung zurückzuführen.

\section{Diskussion}

Die Dextrangelfiltration wurde zur Untersuchung der Serumproteinbindung von Corticosteroiden erstmals von DE Moor u. Mitarb. [47] benutzt. Die Autoren bestimmten vorwiegend die Bindungskapazität, d. h. die Menge von Cortisol, die sich nach in vitroÜberladung und Äquilibrierung des Plasma mit Cortisol in der Proteinfraktion fand. Die schwache Bindung von Cortisol an Albumin wird bei der Dextran. gelfiltration vollkommen aufgehoben $[19,47,49]$. Das Dextrangel bewirkt einerseits als ,Molekülsieb" eine Auftrennung nach der Molekülgröße, andererseits spielen Adsorptionsvorgänge vor allem für die Chromatographie aromatischer Verbindungen eine Rolle $[18$, 23, 70]. Durch diese Adsorptionsvorgänge wird besonders bei Gelen mit geringer Wasseraufnahme wie dem Sephadex G-10 die Elution verzögert. Offensichtlich tritt durch Kompetition der Serumproteine und des Dextrangels um Cortisol auch eine gewisse Dissoziation des Protein-Cortisol-Komplexes auf der

2. Für die Blutentnahmen danken wir Herm Dr. GAstropH, I. Univ.-Frauenklinik, Münohen. 
Dextrangelsäule auf (Abb. 3). Daher, und weil unsere in vitro-Untersuchungen bei Zimmertemperatur ausgeführt wurden, messen wir keineswegs die physiologischen Bindungsverhältnisse und sprechen von sog. freiem Cortisol. Bei konstanten Bedingungen liefert die Methode jedoch gut reproduzierbare und klinisch brauchbare Ergebnisse zur Differenzierung der Nebennierenrindenfunktion. - Das kompetitive Verhalten der beiden Receptoren CBG und Dextrangel geht auch daraus hervor, daß bei Steigerung der Elutionsgeschwindigkeit der. Prozentsatz des freien Cortisols abnimmt. Erhöht man die Temperatur, unter welcher die Dextrangelfiltration vorgenommen wird, so findet sich ein zunehmender Anteil an sog. freiem Cortisol $[8,17,74,75]$. Das beruht nicht auf einer Veränderung des CBG, das bis zu einer Temperatur von über $50^{\circ}$ stabil ist $[17,75]$. Es ist deshalb wesentlich, die drei genannten Faktoren konstant zu halten, um vergleichbare Ergebnisse zu erhalten.

Unsere Untersuchungen galten nicht der Cortisolbindungskapazität, sondern der Feststellung der Proteinbindung des endogenen Cortisols bei bestimmten Funktionszuständen der Nebennierenrinde, der sog. spontan proteingebundenen Fraktion [47]. Die von uns gefundene Cortisolbindung an CBG bei gesunden Personen von rund $90 \%$ steht in guter Ubereinstimmung mit den Ergebnissen bei inkompletter Sättigung der Cortisolbindungsplätze [48]. - Problematisch ist die Umrechnung des fluorimetrisch gemessenen Plasma. Cortisols (11.0HCS) in proteingebundenen und sog. freien Anteil, da die fluorimetrischen Werte eine unspezifische Basisfluorescenz von $3-5 \mu \mathrm{g}-\%$ enthalten. Das wirkt sich besonders im Bereich niedriger Cortisolspiegel stark aus. Diese Umrechnung diente hauptsächlich dazu, einen Vergleich zu der in der Literatur angegebenen Bindungskapazität $[19,36,49] \mathrm{zu}$ ermöglichen. Immerhin soll die fluorimetrische Methode (11-OHCS im 24 Std-Urin) mit der Sekretionsrate von Cortisol besser korreliert sein, als die Bestimmung der 17-OHCS $[9,41]$.

Bei Untersuchung der Bindungsverhältnisse nach $A C T H$-Belastung ist zu berücksichtigen, daß sich unter ACTH das Verhältnis von Cortisol und Corticosteron im Plasma erheblich zugunsten von Corticosteron verschiebt [32, 57]. Die fluorimetrische Methode er. faßt beide Corticosteroide, wobei jedoch das normalerweise in sehr geringer Konzentration vorkommende Corticosteron 2,5-3mal stärker fluoresciert als eine entsprechende Menge Cortisol (nach Matringur [40] und eigenen Untersuchungen). Cortisol und Corticosteron kompetieren um die Bindungsplätze des CBG und werden mit gleicher Affinität gebunden $[1,12$, 16, 47, 75, 83]. Daher dürfte der Anstieg des sog. freien Cortisols anter ACTH nicht nur auf einer Zunahme des Gesamtcortisols beruhen, sondern z.T. auch durch Verdrängung des Cortisols von seinen Bindungsplätzen durch Corticosteron verursacht werden. Anders liegen die Verhältnisse beim CushingSyndrom, bei dem nur ausnahmsweise erhöhte Corticosteronspiegel [57] gefunden werden, was mit dem Befund übereinstimmt, daß auch keine so wesentlich vermehrte ACTH-Sekretion bzw. -spiegel nachweisbar sind $[37,60,71,80]$. Bei keiner der untersuchten 10 Personen stieg unter maximaler Stimulierung der Nebennierenrinde der absolute Wert des proteingebundenen Cortisols über $23,6 \mu \mathrm{g}$. $\%$ an. Das stimmt mit der von DE Moor [47, 49] angegebenen normalen Bindungskapazität des CBG gut überein, welche unter ACIH nicht ansteigt.

Experimentelle Untersuchungen zeigten, daß eine Adrenalektomie bei Ratten zu einer gesteigerten Aktivität oder Bindungsfähigkeit des CBG führt [24-26, 81, 82]. Danach wäre denkbar, daß die erhöhte Proteinbindung des radioaktiven Cortisols, die wir bei Nebennierenrindeninsuffizienz oder nach Totaladrenalektomie gefunden haben, auf einer Zunahme der Bindungskapazität beruhen könnte. Klinische Untersuchungen erbrachten dagegen eine normale CBGKapazität bei Addison-Kranken [19, 49]. Unsere Untersuchungen mit Plasma NNR-insuffizienter $\mathrm{Pa}$ tienten, das $2 \mathrm{Std}$ nach oraler Substitution mit $15 \mathrm{mg}$ Hydrocortison entnommen wurde, zeigen, daß hierbei der Absolutwert des proteingebundenen Cortisols von im Mittel 20,9 $\mu \mathrm{g}-\%$ trotz vermehrten Gesamtcortisols nicht über die normale CBG-Bindungskapazität ansteigt.

Bekanntlich kommt es bei der Nebennierenrindeninsuffizienz infolge Natriumverlustes, Kaliumretention und ungenügender renaler Säureausscheidung zu einer metabolischen Acidose, die jedoch, abgesehen von der Addison-Krise, nicht hochgradig ist [35]. Dagegen findet sich beim Cushing-Syndrom eine mäßige hypokaliämische Alkalose. Es wäre denkbar, daß diese Veränderungen des Blut-pH die von uns festgestellte Veränderung der Proteinbindungsverhältnisse ganz oder teilweise verursachen könnte. Es zeigte sich jedoch, daß der Grad der Cortisolbindung nur unwesentlich vom $\mathrm{pH}$ abhängig ist $[3,8,21]$. CHEN fand mittels Ultrafiltration [8], daß mit steigendem $\mathrm{pH}$ eine Tendenz zu gering vermehrter Bindung von Cortisol an Transcortin und auch an Albumin besteht. Diese Veränderung würde dem von uns festgestellten erhöhten Prozentsatz von proteingebundenem Cortisol bei möglicherweise niedrigerem $\mathrm{pH}$ der Plasmen von Addisonpatienten sogar entgegengerichtet sein. Wir haben daher bei unseren Untersuchungen darauf verzichtet, den $\mathrm{pH}$ dex einzelnen Plasmen durch Pufferzugabe konstant zu halten, da andererseits beschrieben ist, daß die Verdünnung von Plasma die Proteinbindung von Cortisol deutlich reduziert [3]. Eine Veränderung des CBG tritt zwisehen $\mathrm{pH} 5-9$ nicht auf [17].

Bei den hypophysektomierten Patienten zeigt sich besonders deutlich, daß die einmalige Bestimmung des Plasmacortisols (11-OHCS) nicht zur Feststellung einer sekundären Nebennierenrindeninsuffizienz ausreicht (Tabelle 2, Abb, 5). Die Vermehrung des proteingebundenen Anteils ist ein empfindlicher Index, sie ist in ihrer Brauchbarkeit etwa der ACTH-Belastung gleichzusetzen (Tabelle 2). In der Literatur [19, 49] wurde über eine normale Cortisolbindungskapazität bei Patienten mit Akromegalie bzw. Hypopituitarismus berichtet.

Unsere Befunde bei den mit Spirolacton (Aldactone behandelten Patienten stehen nicht in Widerspruch zu denen von DE Moor u. Mitarb. [49]. Diese Autoren beschrieben, daß ein Teil des Spirolacton proteingebunden sei und somit bei fluorimetrischer Messung eine erhöhte Transcortinkapazität vortïusche. Nach unseren, allerdings nicht fluorimetrisch, sondem mit radioaitiv markiertem Cortisol durchgeführten Untersuchungen werden die Proteinbindungsverhältnisse von Cortisol durch Aldactono $\$$ nicht beeinflußt.

Zahlreiche Untersuchungen liegen vor über den Einfluß von Oestrogenen bzw. der Gravidität auf die Cortisolbindung durch CBG $[5,14,15,44,45,47,49,50,59,63,75]$. Oestrogene geben bei fluorimetrischer Bestimmung zwar selbst eine Fluorescenz [40, 78], der Anstieg der Plasmacortisolwerte wurde aber auch mit nicht fluorimetrischen Methoden gezeigt. Diese Patienten weisen ein erhöhtes Gesamtcortisol im Plasma ohne Zeichen eines Cushing-Syndroms auf. Der Zunahme des Gesamtcortisols geht ein Ansteigen des cortisolbindenden Globulins voraus $[47,64]$. Von einigen Autoren [5, 17] wurde vermutet, daß ein qualitativer Unterschied zwischen dem normalen CBG und dem durch endogene oder exogene Oestro- 
gene induzierten besteht. Andere Ergebnisse [63, 66, 74] lassen aber annehmen, daB es sich um ein einheitliches Glyko protein handelt. Dow u. Mitarb. [20] haben nachgewiesen, daß die Zunahme der 17-OHCS im Serum von oestrogen behandelten Fatienten ausschlieBlich auf der Zunahme des proteingebundenen Anteils beruht im Gegensatz zum Cushing. Syndrom, bei dem der freie Anteil vermehrt ist $(\mathrm{Abb}$. 5). Fü die biologische Inaktivität des durch Oestrogene erhöhten Plasmacortisols, d. h. des CBG.gebundenen Cortisols, sprechen neben der Tatsache, daß keine Cushing-Symptome be stehen, eine erniedrigte Sekretions- und Umsatzrate und dementsprechend verlängerte Halbwertszeit von Cortisol sowie eine herabgesetzte Ausscheidung von Cortisol und seinen Metaboliten [45, 59]. Die Ultrafiltration zeigt, daB der Pro zentsatz freien Cortisols unter Oestrogenen abnimmt, der Absolutwert dagegen in etwa gleich bleibt. Die Konzentration an ungebundenem Cortisol im Ultrafiltrat bei der Hämodialyse ändert sich unter Oestrogenbehandlung nicht [50].

Der Einfluß der Schilddrüse auf die Nebennierenrindenfunktion ist mehrfach untersucht worden. Es ist bekannt, daß die Gabe von Schilddrüsenhormonen bei Addison-Kranken zu einer Krise führen kann, da der Umsatz von Cortisol beschleunigt wird. Die Funktionsreserve der NNR ist bei Hyperthyreose herabgesetzt, es kann zu einer relativen NNR-Insuffizienz kommen [22, 68]. Die Schwundraten von exogenem Cortisol, Corticosteron und Cortison sind bei Hyperthyreose gesteigert [58], ebenso die synthetischer Corticoide [29]. Dabei ist die Plasmahalbwertszeit des nicht proteingebundenen Cortisols kleiner als die des proteingebundenen, und beide Halbwertszeiten sind geringer als normal [1,3]. Die Ausscheidung der 17 . OHCS im Urin ist bei der Hyperthyreose gesteigert [31, 34, 58]. Umgekehrt liegen die Verhältnisse bei Sehilddrüsenunterfunktion.

Weniger als $1 \%$ von zugeführtem Hydrocortison werden unverändert im Urin ausgeschieden [56]. Das Verschwinden von Cortisol aus dem Plasma wird vor allem durch den Metabolismus in der Leber $[6,56]$ reguliert. Berswe u. Mitarb. $[1,3]$ haben mittels der Ultrafiltration kein erhöhtes freies Cortisol bei der Thyreotoxikose gefunden und sehen diesen Befund bestätigt durch eine normale Ausscheidung von unkonjugiertom Cortisol bei diesen Patienten. Sie schließen daraus, daB die Unterschiede in der Verschwinderate bzw. der Umbaurate von Cortisol bei verschiedenen Funktionszuständen der Schilddrüse nicht durch eine unterschiedliche Proteinbindung, sondern allein durch Veränderungen des hepatischen Cortisolmetabolismus zu erklären seien. In der Tat haben McGunze and ToMrins [42] mit Leberhomogenaten von thyreotoxischen Ratten eine verdoppelte Abbaurate von Cortisol gegenüber normalen Tieren gesehen.

Unser Befund einer Zanahme des sog, freien Cortisols bei Hyperthyreose scheint in gewissem Widerspruch zu stehen. Allerdings haben BEISEL u. Mitarb. [3] das Plasma mit Cortisol überladen und mit Ultrazentrifugation gearbeitet, bei welcher die Bindung an CBG und Albumin gleichzeitig gemessen wird. Dabei könnte eine Zunahme des nicht an CBG gebundenen Cortisols durch Albuminbindung ausgeglichen werden. Puterson hat nachgewiesen, daB im Zustand der Sehilddrüsenüberfunktion bei meist normalen oder gering erhöhten Porter-Silber-Chromogenen im Plasma eine erhöhte Sekretionsrate von Cortisol besteht $[34,58]$. Unsere Befunde weisen darauf hin, daß außer dem beschleunigten Cortisolabbau in der Leber auch eine Vermehrung des sog. freien Cortisols für den rascheren Umsatz eine Rolle spielt. Es braucht dabei infolge der rascheren Hydrierung von Cortisol bei der Hyperthyreose trotz des erhöhten freien Cortisols nicht zu einer vermehrten Ausscheidung von unkonjugiertem Cortisol zu kommen. - Bei der Hypothyreose findet sich im Gegensatz zur Hyperthyreose eine verminderte Sekretionsrate, eine Erhöhung des Prozentsatzes von proteingebundenem Cortisol und ein verlangsamter Abbau in der Leber.

Zusammenfassung. 1. Mittels Dextrangelfiltration wurde nach Inkubation von markiertem Cortisol und Plasma der proteingebundene und der sog. freie Anteil (\%) des endogenen. Plasmacortisols ermittelt und bei gleichzeitiger fluorimetrischer Bestimmung der 11 OHCS auch die Menge proteingebundenen, bzw, sog. freien Cortisols ( $\mu$ g- \%) berechnet.

2. Die diagnostische Brauchbarkeit der Methode wurde bei Patienten mit Nebennierenrindeninsuffizienz, mit Hypophysentumoren, nach Hypophysektomie, mit Cushing-Syndrom mit der fluorimetrischen Bestimmung der 11.OHCS verglichen. Die einfache Bestimmung der Cortisolbindung war bei hypophysektomierten Patienten der Bestimmung der 11-OHCS überlegen und entsprach der aufwendigeren ACTHBelastung.

3. Falsch hohe fluorimetrische 11-OHCS-Spiegel im Plasma unter Spirolacton- oder Oestrogenbehandlung und in der Gravidität lassen sich durch Bestimmung der Cortisolbindung klären. Bei Schilddrüsenüberfunktion war das sog. freie Cortisol im Plasma relativ und absolut vermehrt, bei Schilddrüsenunterfunktion fand sich eine Zunahme des plasmaproteingebundenen Cortisols.

Summary. 1. Following incubation of labeled cortisol and plasma the percentages of protein bound and socalled free endogenous cortisol were determined by means of dextran gel filtration.

2. The diagnostic value of this method was compared with fluorimetric determinations of 11-OHCS for patients with adrenal insufficiency, Cushing-Syndrome, pituitary tumors and after hypophysectomy. In hypophysectomized patients the simple determination of protein bound cortisol was found to correlate well with diagnostic ACTH-infusion tests and to be more sensitive than fluorimetric determinations of 11-OHCS in 9 a.m. plasma.

3. Falsely elevated fluorimetric values of plasma 11-OHCS in patients treated with spirolactone or estrogens, resp. during pregnancy may be recognized through determination of cortisol binding. - In thyrotoxicosis socalled free cortisol was elevated, both relatively and absolutely; in hypothyroidism an increase of protein bound cortisol was found.

\section{Literatur}

1. Beisme, W. R., V. C. Dr Ratnondo, and P. H. Forsham Cortisol transport and disappearance. Ann. intern. Med. 60, 641 (1964).

2. - J. J. Cos, R. Horton, P. V. Chao, and P. H. ForsHAM: Physiology of urinary cortisol excretion. J. clin. Endocr. 24, 887 (1964).

3. - V.C.Di Ratmondo, P. Y. ChaO, J. M. RosNere, and P. H. FonsH.AK: The influence of plasma protein binding on the extraadrenal metabolism of cortisol in normal, hyperthyroid and hypothyroid subjects. Metabolism 18, 942 (1964).

4. Butss, E. L., A. A. Sandberg, D. H. Nelson, and $K$ EIK-NES: The normal levels of 17 -hydroxycorticosteroids in the peripheral blood of man. J. elin. Invest. $32,818(1953)$.

5. Booth, M., P. F. Dixon, C. H. Gray, J. M. Greenaway, and $\mathrm{N} \cdot \mathrm{J}$. Holsess: Protein binding of cortisol in health and in pregnancy. J. Endoer. 23,25 (1961).

6. Brown, H., and E. Evalert JR.: Corticosteroid metabolism in liver disease. Arch. intern. Med. 107, 773 (1961).

7. Bust, J. E.: The physicochemical state of cortisol in blood. Ciba Found. Coll. Endocr. 11, 263 (1957).

8. Ching, P. S., JR., I. H. MrLls, and F. C. BartTER: Ultrafiltration studies of steroid-protein binding. J. Endocr. 28,129 (1961).

9. Cope, C. L.: The adrenal cortex in internal medicine. Brit. med. J. 1966 II, 847. 
10. DaUghaday, W. H.: Binding of corticosteroids by plasma proteins. I. Dialysis equilibrium and renal elearance studies. J. elin. Invest. 35, 1428 (1956).

11. - Binding of corticosteroids by plasma proteins. II. Paper electrophoresis and equilibrium paper electrophoresis. J. clin. Invest, 35, 1434 (1956).

12. - Binding of corticosteroids by plasma proteins. III. The binding of corticosteroid and related hormones by human plasma and plasma protein fractions as measured by equilibrium dialysis. J. clin. Invest. 37, 511 (1958).

13. - Binding of corticosteroids by plasma proteins. IV. The electrophoretic demonstration of corticosteroid binding globulin. J. clin. Invest. 37, 519 (1958).

14. - Binding of corticosteroids by plasma proteins. V. Corticosteroid-binding globulin activity in normal human beings and in certain disease states. Arch. intern. Med. 101,286 (1958).

15. - I. K. KozaK, and O. BTEDERMaN: Corticosteroid binding globulin activity in body fluids and in fetal and maternal plasma. J. clin. Invest. 38, 998 (1959).

16. - Steroid protein interactions. Physiol. Rev. 39, 885 (1959).

17. -, and I. K. Martz: Corticosteroid-binding globulin: Its properties and quantitation. Metabolism 10,936 (1961).

18. Determann, H.: Gelchromatographie. Berlin-Heidelberg. New York: Springer 1967.

19. Don, R. P., R. Frenandez, and U. S. StaL: Measurement of corticosteroid-binding globulin in man. J. elin. Endocr, 24, 1029 (1964).

20. - H. H. ZinnemanN, E. B. Flink, and R. A. Ulstrom; Significance of the eoncentration of nonprotein-bound plasma cortisol in normal subjects, Cushings-syndrome, pregnancy and during estrogen therapy. J. clin. Endocr. 20, 1484 (1960).

21. Farise, R. V., and J. E. PLAGIR: The in vitro red blood cell uptake of $\mathrm{C}^{14}$-cortisol studies of plasma protein binding of cortisol in normal and abnormal states. J. clin. Invest. 41, $53(1962)$.

22. FELBER, J.P., W.J. REDDY, H.A. SHLENKOW, and G.W. THORN: Adrenocortical response to the 48-hour ACTH. Test in myxedema and hyperthyroidism. J. clin. Endocr. 19, 895 (1959).

23. Flodrr, P.: Dextran gels and their application in gel filtration. Diss. Uppsala 1962.

24. GALA, R. R, and U. WESTPHAR: Relationship between the pituitary gland and the corticosteroid binding globulin in the rat. Endocrinology 78, 277 (1966).

25. - - Influence of anterior pituitary hormones on the cortisol binding globulin in the rat. Endocrinology 79, $55(1966)$.

26. - - Further studies on the cortisol binding globulin in the rat: Proposed endocrine control. Endocrinology 79, 67 (1966)

27. Hartog, M., F. Doxle, R. Fraser, and G. F. Joplin: Partial pituitary ablation with implants of gold-198 and Yttrium-90 for acromegaly. Brit. med. J, 1965II, 396.

28. Heinze, H. G., K. W. Frey u. P. C. Scriba: Methoden und Ergebnisse der Schilddrüsenfunktionsdiagnostik im bayerischen Jodmangelgebiet. Fortschr. Röntgenstr. 108, 596 (1968).

29. HoChHEUSER, W., M. MÜLLER-BardORFF, K. SChWARZ u. P. C. Soriba: Fluorimetrische Bestimmung der sog. 11-Hydroxycorticosteroide im Plasma bei Hyperthyreose und bei Nebennierenrindeninsuffizienz. 13. Sympos. Dtsch. Ges. Endocr, Würzburg 1967. BerlinHeidelberg-New York: Springer 1968, S. 298.

30. - - H. Thirler, P. C. Scriba u. K. SchWarz: Klinische Bedeutung der Trennung von proteingebundenem und sog. freiem Anteil des Plasmacortisols mit Hilfe der Dextrangelfiltration. Verh. Dtseh. Ges. inn. Med. 74 (1968) (im Druok)

31. KARL, H. J., и. W. DECKKER: Untersuchungen über Sekretion und Abbau von Cortisol bei Patienten mit Hypo- und Hyperthyreose. 10. Sympos. Dtsch. Ges. Endocr. 1963, S. 198. Berlin-Göttingen-Heidelberg: Springer 1964 .

32. - u. L. R.ATTH: Die Corticosteronsekretion beim Menschen. III. Mitteilung: Die Sekretionsraten von Cor. ticosteron und Cortisol bei Stimulierung der Neben. nierenrinde mit ACTH. Klin. Wsehr. 44, 303 (1966).
33. KAWAI, A., and F. E. YaTes: Interference with feedback inhibition of adrenocorticotropin release by protein binding of corticosterone. Endocrinology 79, 1040 (1966).

34. Kenny, F. M., N. Trurzaeta, C. Preetasombat, F. H. TAYLOR, and C.J. MIGEON: Cortisol produotion rate. VII. Hypothyroidism and hyperthyroidism in infants and children. J. clin. Endocr. 27, 1616 (1967).

35. KR.Ück, F.: Elektrolyt- und Säure-Basen-Haushalt bei Funktionsanomalien der Nebennierenrinde. Schweiz. med. Wschr. 96, 151 (1966).

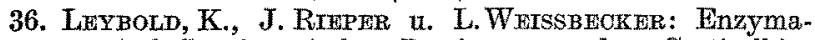
tisch-fluorimetrisehe Bestimmung der Cortisolbindungskapazität des Plasmas. Acta endocr. (Kbh.) 56, 99 (1967).

37. Liddie, G. W., D. IstaAnd, and C. K. Mfador: Normal and abnormal regulation of corticotropin secretion in man. Recent Progr. Hormone Res. 18, 125 (1962).

38. Lowry, O. H., J. N. RoskBrovgr, A. L. FARR, and R. J. RANDALL: Protein measurement with the Folinphenol-reagent. J. biol. Chem. 198, 265 (1951).

39. Matsur, N. and J. E. Prager: In vitro physiologioal activity of protein-bound and unbound cortisol. Endocrinology 78, $1159(1966)$.

40. Matutroty, D.: A simple fluorimetric method for the estimation of free 11-hydroxycorticosteroids in human plasma. J. clin. Path. 15, 374 (1962).

41. - P. M. Dennts, J. Pearson, and C. L. Cope: Rapid screening test for adrenal cortical function. Lancet 1964 II, 1046.

42. MoGorne, J. S., and G. M. Tomrnins: The effects of thyroxin administration on the enzymic reduction of $\Delta_{4}$-3-Ketosteroids. J. biol. Chem. 284, 791 (1959).

43. Mrgeon, C. J., F. H. Tyler, J. P. Mahoney, H. A. Flomentin, H. Castla, E. L. BLISS, and L. T. SAMUELS: The diurnal variation of plasma levels and urinary excretion of 17 -hydroxycorticosteroids in normal subjects, night workers and blind subjects. J. clin. Endocr. 16, $622(1956)$.

44. MrLS, I. H., and F. C. BARTTER: The effect of estrogen administration on the protein binding and metabolism of hydrocortisone. J. Endocr. 18, 5 (1959).

45. Mrris, J. H., H. P. SCHEDL, P. S. CHEN JR., and F. C. BARTTER: The effect of estrogen administration on the metabolism and protein binding of hydrocortisone. J. clin. Endoer. 20, 515 (1960).

46. Moor, P. De, O. Steeno, M. Raskin, and A. Hendetchs: Fluorimetric determination of free plasma Il-hydroxycorticosteroids in man. Acta endocr. (Kbh.) $\mathbf{3 3}$, $297(1960)$.

47. - K. Heirwegh, J. F. Heremans, and M. DeclerckRASKIV: Protein binding of corticoids studied by gel filtration. J. clin. Invest. 41, 816 (1962).

48. - The binding of radiocortisol on transcortin as meas. ured by gel filtration. Pflügers Arch. ges. Physiol. 285,349 (1965).

49. - 0 . Steeno, J. Brosens, and H. Hendrikx: Data on transcortin activity in human plasma as studied by gel filtration. J. clin. Endocr. $\mathbf{2 6}$, 71 (1966)

50. - R. VurB ERCKMOES, and W. HeYNs: Unbound plasma cortisol as measured by ultrafiltration in vivo: Effect of estrogen treatment. J. clin. Endocr. 28,313 (1968).

5l. MÜlller-BardorfF, M., W. HochHeUSER, K. SchWARZ, and P.C. SCRIBA: Effect of ACTH infusion test on cortisol-4-C $\mathrm{C}^{14}$ binding to plasma proteins. VI. Acta Endocr. Congress, Helsinki 1967. Acta endocr. (Kbh.), Suppl. 119, 180 (1967)

52: - Funktionsuntersuchungen der menschlichen Nebennierenrinde mit Hilfe der Bestimmung der sog. 11. OHCS und der Cortisol-Bindungsverhältnisse im Plasma. Diss. Universität München 1968.

53. Muldoon, T. G., and U. Westrehal: Steroid-protein interactions. XV. Isolation and characterization of corticosteroid-binding globulin from human plasma. J. biol. Chem. 242, 5636 (1967).

54. NakajtMa, H., M. MUrata, M. Nakata, T. Naruse, and S. Kuвo: Determination of blood corticoids using the in vitro resin nptake of $3 \mathrm{H}$-prednisolone. Acta endocr. (Kbh.) 57, 23 (1968).

55. Perkoff, G. T., K. Ein-Nes, C. A. Nugent, H. L. Freid, R. A. NLMER, L. RUSh, L.T. SAMUUEL, and F.H. Truer: Studies of the diurnal variation of plasma 
17-hydroxycorticosteroids in man. J. clin. Endocr. $19,432(1959)$.

56. Peterson, R.E., J.B.Wymgaarden, S.I. Guerra, B.B. Bropre, and J. J. BumrM: The physiological disposition and metabolic fate of hydrocortisone in man. J. clin. Invest. 34, 1779 (1950)

57. - Plasma corticosterone and hydrocortisone levels in man. J. clin. Endocr. 17, 1150 (1957)

58. - The influence of the thyroid on adrenal cortical function. J. clin. Invest. $37,736(1958)$.

59. - G. Nokes, P. S. Chen JR., and R. L. Btack: Estrogens and adrenocortical function in man. J. clin. Endocr. 20, 495 (1960).

60. Pfeiffer, E. F., E. Garmendota, E. Vaubex u. K. RuTIENE: Exogene und endogene ACTH-Aktivitäten im nativen Plasma des Menschen. Ergebn. inn. Med. Kinderheilk., N.F. 20, 127 (1963)

61. Quincex, R. V., and C. N. GraY: A comparison of protein-binding of cortisol as measured by equilibrium dialysis and gel filtration. J. Fndocr. $\mathbf{2 6}, 509$ (1963)

62. Roginsky, M. S., J. C. Shaver, and N. P. Christy: study of adrenal cortical function in acromegaly. $J$ clin. Endocr. 26, 1101 (1966).

63. SandBerg, A. A., and W. R. Staunwhirte, JR.: Transcortin: A corticosteroid binding protein of plasma. II. Levels in various conditions and the effeets of estrogens. J. clin. Invest. 38, 1290 (1959).

64. - - and A. C. CARTER: Transcortin: A corticosteroid. binding protein of plasma. III. The effects of various steroids. J. clin. Invest. 39, $1914(1960)$.

65. - - Transcortin: A corticosteroid-binding protein of plasma. V. In vitro inhibition of cortisol metabolism. J. clin. Invest. 42, 51 (1963).

66. - M. Woodrutf, H. Rosentuat, S. NTENHouse, and W. R. StadNWHITt: Transcortin: A corticosteroidbinding protein of plasma. VII. Half-life in normal and estrogen-treated subjects. J. clin. Invest. 43, 461 (1964).

67. SCHEDL, H. P., P. S. ChEN, G. GRHENE, and D. REDD: The renal clearance of plasma cortisol. J. clin. Endocr. $19,1223(1959)$.

68. ScHWARZ, K.: Zur Frage der Nebennierenrindenfunktion bei Erkrankungen der Schilddrüse. I. Mitt.: Hyperthyreosen und thyreotoxische Krise. Klin. Wschr. 37, $654(1959)$.

69. - P. Dteterle, W. Hochheuser, A. KollmannsberGER, M. MülLer-BardorfF u. P. C. Scriba: Zur Klinik der Nebennierenrindeninsuffizienz. Med. Klin. 62, $55 \mathrm{I}(1967)$.

70. Scriba, P.C., R. Landgraf, H. G. Hetnge u. K. Schwarz: Bestimmung der Bindung von Trijodthyronin an Serumproteine mittels Dextrangelfiltration. Klin. Wschr. 44, 69 (1966).

71. - R. Hacker, P. Dieterle, F. Kluge, W. HochHeU SER u. K. SCHWARZ: ACTH-Bestimmungen im Plasma aus dem Bulbus cranialis venae jugularis. Klin. Wschr. 44, $1393(1966)$.
72. SCRIBA, P.C., K. v. WERDER, J. RICHTER U. K. SOHWARZ: Ein Beitrag zur klinischen Diagnostik des ektopischen ACTH-Syndroms. Klin. Wschr. 46, 49 (1968).

73. Sest, U. S., and R. P. DoE: Purification and properties of "transcortin", the cortisol binding globulin. Fed. Proc. 20, 179 (1961).

74. - - Corticosteroid-binding globulin. I. Isolation from plasma of diethylstilbestrol-treated men. J. biol. Chem. 237, 3136 (1962).

75. Slaunweite, W. R., JR., and A. A. SANDberg: Transcortin: A corticosteroid-binding protein of plasma. $J$. elin. Invest. 38, 384 (1959).

76. - G. N. LockIB, N. BACK, and A. A. SANDBERG: Inactivity in viro of transcortinbound cortisol. Science 135., 1062 (1962)

77. ThreLE, H.: Diss. Universität München (in Vorbereitung).

78. UDFNERIED, S.: Fluorescence assay in biology and medicine, p. 349-371. New York and London: Acad. Press 1962.

79. UPTON, G. V., and P. K. Bondy: The binding of cortisol by plasma protein. Arch. Biochem. 78, 197 (1958).

80. VANCE, V. K., J. W. ReodX, D. H. Nelson, and G. W. THORN: ACTH in human plasma. J. clin. Invest. 41, $20(1962)$.

81. Westrhax, U., W. C. Willuams, and B. D. Ashlegy: In. creased corticosteroid binding activity in adrenal ectomized and hypophysectomized rats. Proc. Soc. exp. Biol. (N.Y.) 109, 926 (1962).

82. - W. C. WILliams JR., B. D. AshlegY, and F. DE VENUTO: Proteinbindung der Corticosteroide im Serum adrenalektomierter und hypophysektomierter Ratten. Hoppe-Seylers Z. physiol. Chem. 332, 54 (1963).

83. - Steroid-proteininteractions. XII. Distribution of progesteron and corticosteroid hormones among serum proteins. Hoppe-Seylers Z. physiol. Chem. 346, 243 (1966).

84. WinkelaranN, W., H. Berhge, H. Schmirt, H. G. SolBACH, D. Vorster u. H. ZTMMERMANN: Cortisol und Corticosteronsekretion bei der Akromegalie. Klin. Wschr. 46, 1008 (1968).

85. Wiss. Tab. Geigy, 6. Aufl. (1960).

86. Wood, J. B., A. W. FrankLand, V. H. T. JAMES, and J. LANDON: A rapid test of adrenocortical function. Lancet 1965 I, 243 .

87. YATES, F. E., and J. URQuHART: Control of plasma concentrations of adrenocortical hormones. Physiol. Rev. 42, $359(1962)$.
Dr. med. W. HochHEuser
Dr. med. M. MÚ́LLER-BAEDORFF
Prof. Dr, med. K. Schwarz
Priv.-Doz. Dr. med. P. C. Scriba
cand. med. H. THIFLE
II. Med. Klinik der Universität München
8 München 15, Ziemssenstr. 1 a
Prof. Dr, med. F. MaRgUTH
Neurochirurgische Univ.-Klinik München

\title{
Die intestinale Resorption des Nahrungs-Eisens aus dem Hämoglobin, der Leber und Muskulatur bei Menschen mit normalen Eisenreserven und Personen mit prälatentem/latentem Eisenmangel *
}

\author{
H. C. Heinrich, H. Bartels, E. E. GabBe, B. Metnfeke, W. P. Nass und D. H. Whang
}

Abteilung für Medizinische Biochemie (Vorstand: Prof. Dr. med. H. C. Herrarar) am Institut für Physiologische Chemie (Direktor: Prof. Dr. med. J. Kü̈nav) der Universität Hamburg

Die weltweite Verbreitung von Eisenmangelanämien insbesondere bei menstruierenden und graviden Frauen sowie die Beobachtung, daß der durch eine Erschöpfung der Gesamtkörpereisenreserven charakterisierte prälatente Eisenmangel der beim Menschen

* Auszugsweise vorgetragen auf dem Western Hemisphere Nutrition Congress II, Research Forum, p. 36, San Juan/Puerto Rico, 26.-29. August 1968. am häufigsten vorkommende Mangelzustand überhaupt ist (vgl. HenNRrCH, 1967, 1968), machen eine wirksame diätetische oder medikamentöse Eisenpro. phylaxe und Therapie erforderlich. Obwohl inzwischen ein gut resorbierbares und auch gut verträg* liches orales Eisenpräparat entwickelt und bei der medikamentösen Prophylaxe und Therapie der verschiedenen Eisenmangelzustände ausreichend erprobt 